03

\title{
О связи ширины зоны турбулентного горения с составом топлива, давлением, скоростью распространения и электропроводностью пламени
}

\author{
(C) А.П. Шайкин, И.Р. Галиев \\ Тольяттинский государственный университет, \\ 445667 Тольятти, Россия \\ e-mail: sbs777@yandex.ru
}

Поступило в Редакцию 21 февраля 2019 г.

В окончательной редакции 31 мая 2019 г.

Принято к публикации 19 января 2020 г.

\begin{abstract}
Представлены результаты экспериментального изучения взаимосвязи ширины зоны турбулентного горения (ЗТГ) с составом композитного топлива (hythane), максимальным давлением в камере сгорания переменного объема, скоростью распространения и электропроводностью турбулентного пламени. Выявлено, что ширина ЗТГ имеет характерную зависимость от состава hythane. Экспериментально обнаружено, что, несмотря на изменение коэффициента избытка воздуха, концентрации водорода в топливе, интенсивности турбулентности и вида топлива (hythane и бензин), сохраняются неизменными зависимости ширины ЗГТ от турбулентной скорости распространения пламени и от электропроводности пламени, а также зависимость максимального давления от ширины ЗТГ. Результаты работы могут быть использованы при проектировании и доводке энергоэффективных и малоэмиссионных камер сгораний.
\end{abstract}

Ключевые слова: пламя, электропроводность, ширина пламени, скорость распространения пламени.

DOI: $10.21883 /$ JTF.2020.07.49437.65-19

\section{Введение и постановка задачи}

В связи с постоянным ростом цен на топливо и законодательным ужесточением концентрации токсичных компонентов в выхлопных газах энергоустановок остаются актуальными вопросы дальнейшего улучшения их экологических и энергетических характеристик. Одним из наиболее быстрореализуемых способов решения данной проблемы является использование композитных топлив. В последнее два десятилетия ученые и инженеры ведущих стран мира уделяют большое внимание новому топливу hythane - смеси природного газа с водородом [1,2]. В США, Китае, Индии и Норвегии действуют программы государственной поддержки потребителей hythane $[3,4]$. Это обусловлено тем, что использование hythane способствует значительному снижению токсичности выхлопа двигателя и повышению его тягово-динамических показателей $[5,6]$. Кроме этого, имеется возможность использовать действующие газонаполнительные компрессорные станции и газобаллонное оборудование для заправки двигателей hythane, при этом стоит отметить, что стоимость hythane сопоставима со стоимостью бензина, что делает перспективным его использование с экономической точки зрения.

Для создания новых малоэмиссионных и энергоэффективных камер сгораний (КС), использующих hythane, необходимо глубокое изучение процесса сгорания композитного топлива. Процесс сгорания композитного углеводородного топлива в поршневых энергоустановках представляет собой сложный физико-химический про- цесс, протекающий при изменении в течение нескольких миллисекунд: давления, температуры, объема КС, масштаба и интенсивности турбулентности, ширины зоны турбулентного горения (ЗТГ), турбулентной и нормальной скоростей распространения пламени. В настоящее время остается малоизученным влияние на ширину ЗТГ химического состава композитного топлива (т.е. hythane), скорости распространения и электропроводности турбулентного пламени. Отсутствуют данные о взаимосвязи ширины ЗТГ с максимальным давлением сгорания в КС переменного объема. Исследования в данной области необходимы для создания новых энергетических установок, использующих hythane и соответствующих современным требованиям по мощности, экономичности и токсичности.

Цель работы: изучить связь ширины зоны турбулентного горения с составом композитного топлива (hythane), максимальным давлением в камере сгорания переменного объема, скоростью распространения и электропроводностью турбулентного пламени.

\section{Методика проведения экспериментов}

Эксперименты проводились в КС переменного объема с искровым зажиганием [7]. В качестве топлива использовался hythane. Методика эксперимента заключалась в параллельной регистрации сигналов с искры зажигания, датчика расхода воздуха, датчика давления и ионизационного датчика (ИД). Варьируемыми факторами в экспериментах являлись: частота вращения коленчатого 
вала двигателя $\left(n=600\right.$ и $\left.900 \mathrm{~min}^{-1}\right)$, коэффициент избытка воздуха $(\alpha)$ и концентрация водорода в hythane, составляющая $r_{\mathrm{H}}=29,47$ и 58\% (по объему). Ширина ЗТГ определялась по формуле (1):

$$
\begin{gathered}
\delta=U_{a v} \cdot t-D \\
U_{a v}=\frac{L}{t},
\end{gathered}
$$

где $U_{a v}$ - средняя скорость распространения пламени $[\mathrm{m} / \mathrm{s}] ; t_{s}$ - продолжительность сигнала ионного тока $[\mathrm{s}] ; D$ - диаметр электрода ИД $[\mathrm{m}] ; L-$ расстояние от свечи зажигания до электрода ИД $[\mathrm{m}], t$ - промежуток времени от начала зажигания до появления ионного тока в ИД [s].

Для придания исследуемой связи большей универсальности, т.е. независимости от формы КС и газодинамических характеристик, все значения представлены в относительных величинах — отношения анализируемых параметров к параметрам при стехиометрическом составе смеси, как это представлено для ширины 3ТГ:

$$
\delta_{\text {rel }}=\frac{\delta_{\alpha=x}}{\delta_{\alpha=1}}
$$

где $\delta$ - ширина ЗТГ при стехиометрическом составе топливовоздушной смеси (ТВС), м; $\alpha-$ коэффициент избытка воздуха; $x$ - текущее значение коэффициента избытка воздуха.

\section{Экспериментальные результаты и их обсуждение}

Исследование ширины ЗТГ показало, что при коэффициентах избытка воздуха от 0.9 до 1.1 увеличение интенсивности турбулентности в 1.5 раза (достигаемое за счет роста частоты вращения коленчатого вала двигателя с 600 до $900 \mathrm{~min}^{-1}$ ) не приводит к заметному изменению ширины ЗТГ. Так, изменение $\delta_{r e l}$ при коэффициенте избытка воздуха $\alpha=1$ составило всего $2 \%$.

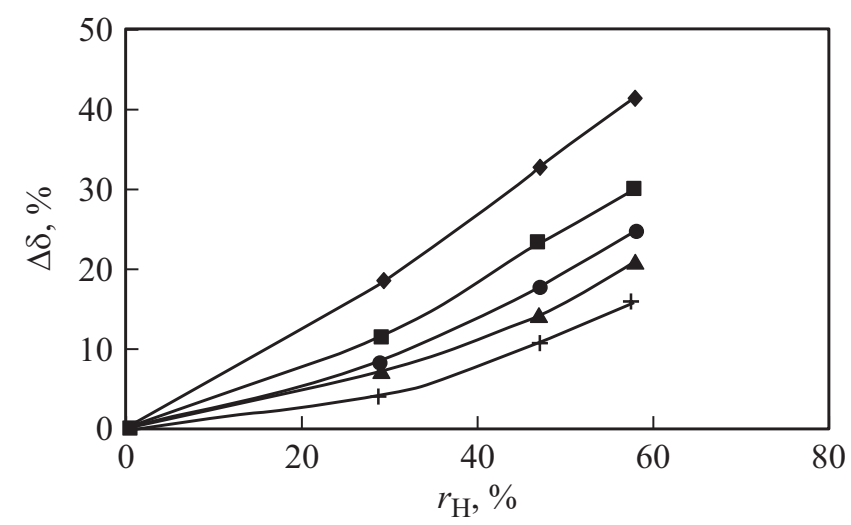

Рис. 1. Зависимость уменьшения ширины ЗТГ от коэффициента избытка воздуха и концентрации водорода, $\alpha:+-0.9$; $\boldsymbol{\Delta}-1 ; \bullet-1.1 ; \mathbf{\square}-1.2 ;-1.3$.

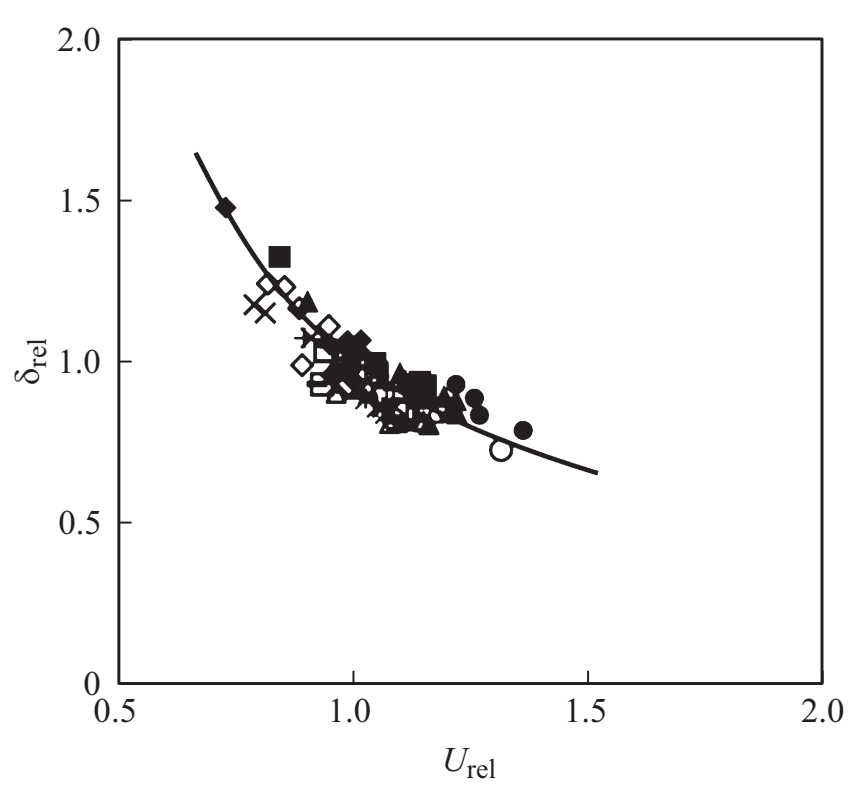

Рис. 2. Связь ширины ЗТГ со скоростью распространения пламени: $\diamond, \square, \triangle, \circ, \diamond, \mathbf{\square}, \mathbf{\Delta}, \bullet-$ hythane; $-, \star, \times,+-$ бензин $+\mathrm{H}_{2} ; \diamond, \square, \circ,-, \star, \times-n=600 \mathrm{~min}^{-1} ; \diamond, \mathbf{\square}, \boldsymbol{\Delta}, \bullet$, $+-n=900 \mathrm{~min}^{-1} ; \diamond, \diamond, \times,+-r_{\mathrm{H}}=0 \% ; \star-r_{\mathrm{H}}=19 \%$; $-, \mathbf{\square}, \square-r_{\mathrm{H}}=29 \% ; \boldsymbol{\Delta}, \triangle-r_{\mathrm{H}}=47 \% ; \bullet, \circ-r_{\mathrm{H}}=58 \%$.

Это обусловлено тем, что при $\alpha$ от 0.9 до 1.1 горение описывается моделью микроламинарного пламени. Турбулентные вихри не проникают в ЗТГ, а только меняют ее конфигурацию, поэтому увеличение $\mathrm{n}$ приводит к увеличению площади поверхности фронта пламени и скорости распространения пламени, но ширина ЗТГ остается неизменной. При $\alpha=1.2$ рост интенсивности турбулентности привел к увеличению ширины ЗТГ на $8 \%$, а при $\alpha=0.8$ ширина пламени увеличилась на $7 \%$. Это объясняется тем, что при сжигании бедных и богатых смесей ширина ламинарного пламени увеличивается, турбулентные вихри проникают в ЗТГ и влияют на кинетику химических реакций. Турбулентность потока приводит разрыву и растяжению ЗТГ, поэтому $\delta_{\text {rel }}$ увеличивается. Отметим, что обработка экспериментальных данных, полученных на бензопоршневой моторной установке [8] выявила схожее поведение ширины ЗТГ при увеличении частоты вращения коленчатого вала с 600 до $900 \mathrm{~min}^{-1}$. В частности, при $\alpha=1$ ширина ЗТГ увеличилась на $4 \%$, а при $\alpha=1.2$ прирост $\delta_{\text {rel }}$ составил $9 \%$, при этом добавка водорода в ТВС практически не влияет на выявленную закономерность.

Анализ экспериментальных значений ширины ЗТГ также выявил, что чем ближе коэффициент избытка воздуха к единице, тем тоньше ширина ЗТГ. Это объясняется тем, что при стехиометрическом составе ТВС $(\alpha=1)$ скорость химических реакций имеет максимальное значение, в результате увеличивается нормальная скорость пламени и уменьшается ширина ЗТГ. Обнаружено, что добавление водорода приводит к уменьшению ширины ЗТГ (рис. 1). Данный эффект объясняется возрастанием 


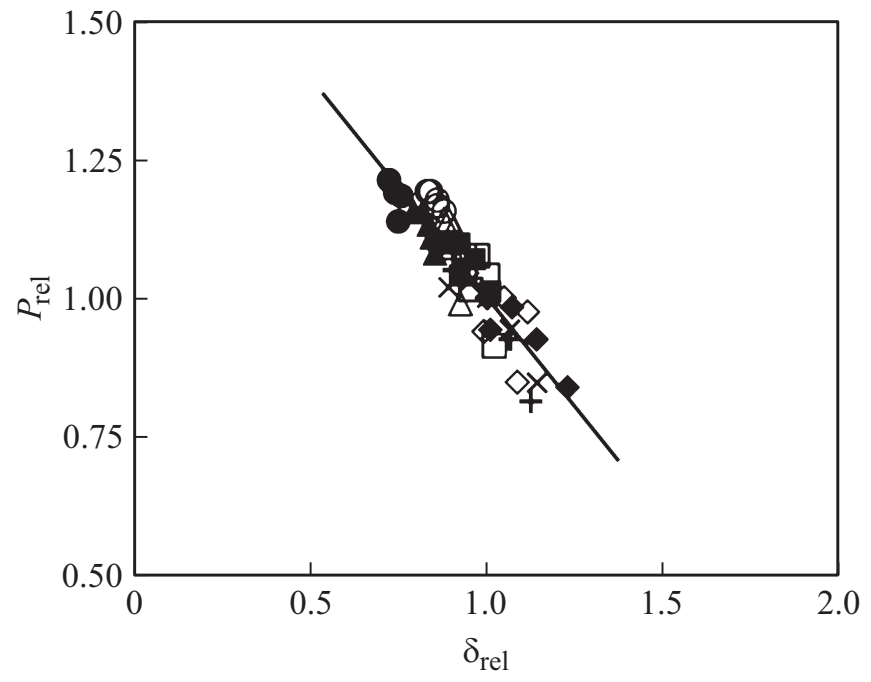

Рис. 3. Связь максимального давления $\left(P_{r e l}\right)$ в КС с шириной ЗТГ: $\diamond, \square, \triangle, \circ, \diamond, \mathbf{\square}, \mathbf{\Delta}, \bullet-$ hythane; $\times,+-$ бензин $+\mathrm{H}_{2}[8]$; $\diamond, \square, \triangle, \circ, \times-n=600 \mathrm{~min}^{-1} ; \diamond, \mathbf{\square}, \mathbf{\Delta}, \bullet,+-n=900 \mathrm{~min}^{-1}$; $\diamond, \diamond, \times,+-r_{\mathrm{H}}=0 \% ; \mathbf{\square}, \square-r_{\mathrm{H}}=29 \% ; \mathbf{\Delta}, \triangle-r_{\mathrm{H}}=47 \%$; $\bullet, \circ-r_{\mathrm{H}}=58 \%$.

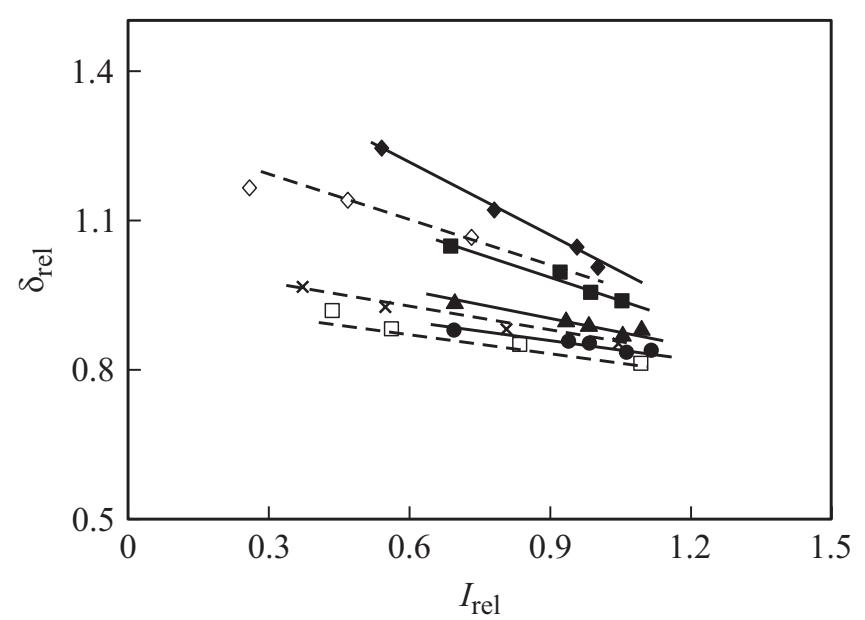

Рис. 4. Связь ширины ЗТГ пламени с электропроводностью пламени: $\downarrow, \boldsymbol{\square}, \boldsymbol{\Delta}, \bullet-$ hythane; $\diamond, \times, \square-$ бензин $+\mathrm{H}_{2}$ [7]; $\diamond$, $\diamond-r_{\mathrm{H}}=0 \% ; \times-r_{\mathrm{H}}=19 \% ; \mathbf{\square}, \square-r_{\mathrm{H}}=29 \% ; \boldsymbol{\Delta}, \Delta-$ $r_{\mathrm{H}}=47 \% ; \bullet, \circ-r_{\mathrm{H}}=58 \%$.

нормальной скорости пламени, которая отражает интенсивность химических реакций в ЗТГ. Чем выше нормальная скорость распространения пламени, тем быстрее сгорает топливо и сильнее сокращается ЗТГ. Отмечено, что уменьшение ширины ЗТГ усиливается с увеличением коэффициента избытка воздуха (рис. 1). Это связано с тем, что в бедных ТВС количество основного углеводородного топлива меньше, чем в богатых ТВС, поэтому при $\alpha>1$ влияние добавок водорода на процесс сгорания становится более заметным. Так, например, при $\alpha=1$ добавка 58\% водорода привела к сокращению ЗТГ на $20 \%$, а для $\alpha=1.2$ уменьшение ширины ЗТГ составило 29\%. Сравнение полученных результатов с исследованиями российских [8] и зарубежных [9] ученых показало схожее поведение ширины ЗТГ при добавках водорода в ТВС. Например, в работе [8] при изучении влияния микродобавок водорода на ширину ЗТГ было обнаружено, что при $\alpha=0.8$ добавка $r_{\mathrm{H}}=19 \%$ приводит к 7\% уменьшению ширины ЗТГ, а при $\alpha=1.3$ такая же добавка водорода уменьшила ширину ЗТГ уже на $21 \%$.

На рис. 2 представлена связь ширины ЗТГ со скоростью распространения пламени. Экспериментально обнаружено, что, несмотря на изменение коэффициента избытка воздуха, концентрации водорода в ТВС, интенсивности турбулентности и вида топлива (hythane и бензин), сохраняется степенная зависимость ширины ЗТГ от турбулентной скорости распространения пламени. При этом уменьшение $\delta_{\text {rel }}$ соответствует увеличению $U_{\text {rel }}$. Схожее поведение $\delta_{r e l}$ при изменении $U_{r e l}$ выявлено при анализе исследований, проведенных российскими учеными на бензопоршневом двигателе [8], а также работ шведских ученых из технического университета Чалмерса [10]. Также на рис. 2 видно, что при снижении скорости пламени ширина ЗТГ стремится к максимуму, т.е. когда режим горения приобретает черты реактора идеального перемешивания, отсутствуют четкие границы между зонами сгоревшей и несгоревшей ТВС и весь процесс сгорания представляет собой одну сплошную ЗТГ. С другой стороны, анализ графика показывает, что, как бы ни была высока скорость распространения пламени, ширина ЗТГ никогда не будет равна нулю. Полученные результаты соответствуют и подтверждают современные представления теории турбулентного горения в условиях двигателя внутреннего сгорания с искровым зажиганием [11].

На рис. 3 представлена связь максимального давления в КС с шириной ЗТГ при изменении коэффициента избытка топлива, концентрации водорода в топливе (hythane и бензин) и интенсивности турбулентности. Обнаружено, что, несмотря на изменение варьируемых в эксперименте факторов, сохраняется линейная зависимость максимального давления в КС от ширины ЗТГ. При этом сокращение $\delta_{\text {rel }}$ соответствует увеличению $P_{\text {rel }}$. Это объясняется тем, что чем меньше $\delta_{r e l}$, тем выше скорость распространения пламени и интенсивность сгорания топлива в ЗТГ. В результате при сгорании выделяется больше тепла, а само топливо сгорает в меньшем объеме, что приводит к росту $P_{r e l}$.

На рис. 4 представлена связь ширины ЗТГ пламени с электропроводностью пламени (оцениваемой амплитудой ионного тока). Выявлено, что, несмотря на изменение коэффициента избытка воздуха, концентрации водорода в ТВС и вида топлива (hythane и бензин), сохраняется линейная зависимость ширины ЗТГ от амплитуды ионного тока $\left(I_{r e l}\right)$. При этом увеличение $I_{r e l}$ соответствует уменьшению $\delta_{r e l}$, т. е. чем выше электропроводность пламени, тем меньше ширина ЗТГ. Так, например, для $r_{\mathrm{H}}=0 \%$ увеличение $I_{r e l}$ с 0.55 до 1 соответствует уменьшению ширины ЗТГ $\delta_{\text {rel }}$ с 1.25 
до 1; для бензовоздушной смеси при тех же условиях увеличение $I_{\text {rel }}$ с 0.3 до 1 соответствует уменьшению ширины ЗТГ $\delta_{\text {rel }}$ с 1.2 до 1 . Это объясняется тем, что значение ионного тока характеризует интенсивность химических реакций в ЗТГ — чем выше ток, тем выше скорость химических реакций и, значит, меньше ширина 3ТГ. Также на рис. 4 видно, что чем больше добавка водорода, тем слабее корреляция между ионным током и шириной ЗТГ. Это связано с тем, что при добавке водорода в интервале от 29 до 58\% ионный ток практически не меняется (так как увеличение $I_{\text {rel }}$ за счет роста скорости химических реакций, обусловленного добавкой водорода, компенсируется снижением $I_{r e l}$ изза уменьшения концентрации углерода [7]), в отличие от ширины ЗТГ пламени.

\section{Заключение}

1. Выявлено, что ширина ЗТГ имеет характерную зависимость от состава hythane - чем ближе коэффициент избытка воздуха к единице и больше концентрация водорода в топливе, тем меньше ширина ЗТГ.

2. Экспериментально обнаружено, что, несмотря на изменение коэффициента избытка воздуха, концентрации водорода в топливе, интенсивности турбулентности и вида топлива (hythane и бензин), сохраняются неизменными следующие зависимости: а) степенная зависимость ширины ЗТГ от турбулентной скорости распространения пламени - чем выше скорость пламени, тем меньше ширина ЗТГ; б) линейная зависимость ширины ЗТГ от электропроводности пламени - чем больше электропроводность пламени, тем меньше ширина ЗТГ; в) линейная зависимость максимального давления от ширины ЗТГ - чем меньше ширина ЗТГ, тем выше давление.

3. Обработка результатов зарубежных и отечественных ученых показала справедливость полученных нами закономерностей для камер сгораний разных конструкций, использующих разное углеводородное топливо.

\section{Финансирование работы}

Работа публикуется при поддержке Министерства науки и высшего образования РФ в рамках программы назначения стипендии президента РФ для молодых ученых СП-3204.2018.1.

\section{Конфликт интересов}

Авторы заявляют, что у них нет конфликта интересов.

\section{Список литературы}

[1] Sandalcı T., Galata S., Karagoz Y. // Int. J. Hydrogen Energy. 2019. N 5. P. $3208-3220$.

[2] Tangoz S., Kahraman N. // Int. J. Hydrogen Energy. 2017. N 5. P. 25766-25780.
[3] Mariani A. Review of Hydrogen-Natural Gas Blend Fuels in Internal Combustion Engines. In Tech. Europe, 2012. 325 p.

[4] Ma F. Hydrogen-Enriched Compressed Natural Gas as a Fuel for Engines. Natural Gas, 2010. 606 p.

[5] Verma G., Prasad R.K., Agarwal R.A. // Fuel. 2016. N 178. P. 209-217.

[6] Shaikin A.P., Galiev I.R. // Russ. Aeronautics. 2016. Vol. 59. P. 249-253.

[7] Шайкин А.П., Галиев И.Р. // ЖТФ. 2016. Т. 86. Вып. 8. C. 87-89. [Shaikin A.P., Galiev I.R. // Tech. Phys. 2016. N 8. P. 1206-1208.]

[8] Дерячев А.Д. Эмпирическая модель оценки концентрации оксидов азота при добавке водорода в ТВС двигателей с искровым зажиганием. Тольятти, 2015. 150 с.

[9] Hermanns R.T. Laminar Burning Velocities of MethaneHydrogen-Air Mixtures. Universal Press, 2007. 144 p.

[10] Lipatnikov A.N., Chomiak J. // Prog. Energy Combust. Sci. 2002. N 28. P. $1-74$.

[11] Peters N. Combustion Theory. Princeton, 2010. 285 p. 